PROFESIONALES Y HERRAMIENTAS PARA EL DESARROLLO LOCAL Y SUS SINERGIAS TERRITORIALES. EVALUACIÓN Y PROPUESTAS DE FUTURO IX Coloquio Nacional de Desarrollo Local del GTDL-AGE 

ANTONIO MARTÍNEZ PUCHE, XAVIER AMAT MONTESINOS, ISABEL SANCHO CARBONELL y DANIEL SANCHIZ CASTAÑO (EDS.)

\section{PROFESIONALES Y HERRAMIENTAS PARA EL DESARROLLO LOCAL Y SUS SINERGIAS TERRITORIALES. EVALUACIÓN Y PROPUESTAS DE FUTURO}

IX Coloquio Nacional de Desarrollo Local del GTDL-AGE

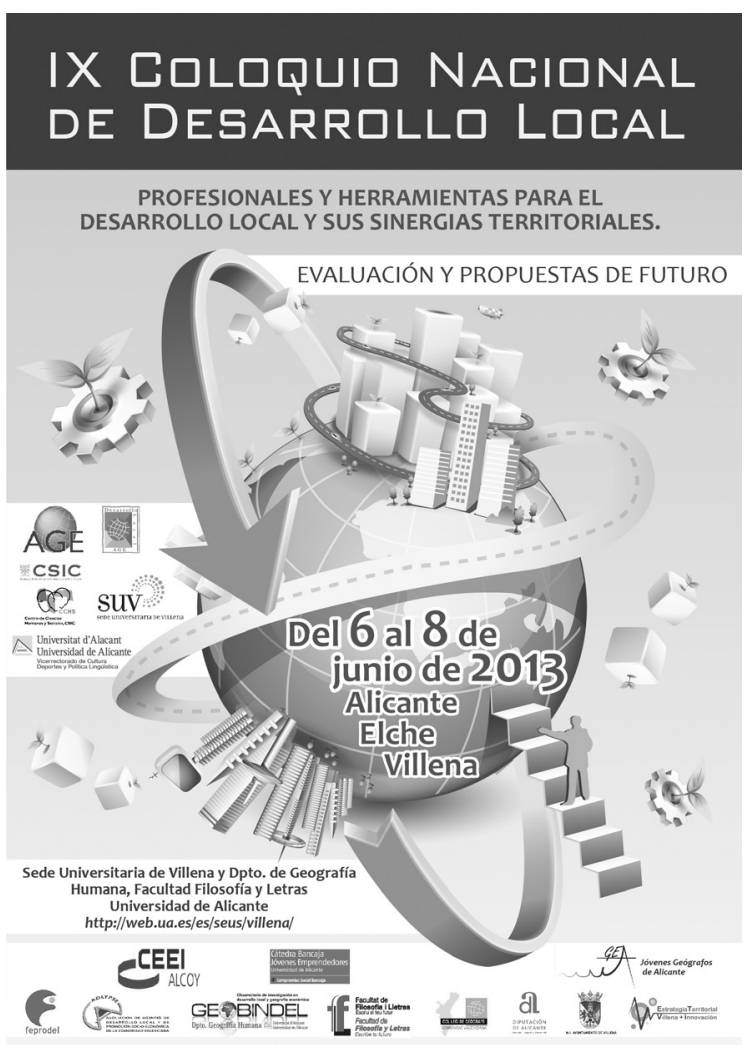


Este libro ha sido examinado y valorado por evaluadores ajenos a la Universidad de Alicante, con el fin de garantizar la calidad científica del mismo.

Publicacions de la Universitat d'Alacant

03690 Sant Vicent del Raspeig

Publicaciones@ua.es

http://publicaciones.ua.es

Telèfon: 965903480

(C) Antonio Martínez Puche, Xavier Amat Montesinos,

Isabel Sancho Carbonell y Daniel Sanchiz Castaño (eds.), 2016

(C) d'aquesta edició: Universitat d'Alacant

ISBN: 978-84-16724-00-0

Dipòsit legal: A 92-2016

Disseny de coberta: candela ink

Composició: Página Maestra (Miguel Ángel Sánchez Hernández)

Impressió i enquadernació: Guada Impresores

\section{unte \\ Unión de Editoriales
Universitarias Españolas \\ WWW.une.es
WWA}

Esta editorial es miembro de la UNE, cosa que garantiza la difusión y comercialización nacional y internacional de sus publicaciones.

Reservados todos los derechos. Cualquier forma de reproducción, distribución, comunicación pública o transformación de esta obra sólo puede ser realizada con la autorización de sus titulares, salvo excepción prevista por la ley. Diríjase a CEDRO (Centro Español de Derechos Repográficos, www.cedro.org) si necesita fotocopias o escanear algún fragmento de esta obra. 


\title{
PROFESIONALES DEL DESARROLLO LOCAL, ACCIONES, LOGROS Y RETOS DE FUTURO
}

\author{
Pilar Clemente Ramón \\ Agencia para el Desarrollo Económico y Social de Petrer. ADLYPSE \\ pclemente@petrer.es
}

RESUMEN

Quiero mostrar quienes somos los profesionales del desarrollo local. Que rasgos y valores nos inspiran; que actividades realizamos; la importancia de habernos constituido en asociaciones y de caminar hacia el colegio profesional. También describiré la problemática actual que se centra en una crisis del municipalismo, por los problemas de financiación y los cambios competenciales de la nueva de la Ley de Bases a punto de entrar en vigor. Y por último señalar el impulso que el Comité de las Regiones puede dar a la profesión con el instrumento del "Desarrollo Local Participativo".

Palabras claves: desarrollo local; adl; comité de las regiones; ley de bases; municipalismo.

\section{"LOCAL DEVELOPMENT PROFESSIONALS: ACTIONS, ACHIEVEMENTES AND FUTURE CHALLENGES"}

\section{ABSTRACT:}

I want to show who are the local development professionals. What features and values inspire us, the activities we do, the importance of being constituted in partnerships and being walking towards the professionalism. Also I will describe the current problem that focuses on the crisis of municipalism, due to the funding problems and competence changes of the new "Bases Law" that will be approved soon. And finally, indicate the boost that the Regions Committee can give to the profession with the instrument of "Participatory Local Development".

Key words: Local development; ADL (agent local development); Regions Committee; Bases Law; municipalism. 


\section{¿QuiÉNes SOMOS?}

Antes de entras en materia, como presidenta, os quiero presentar a ADLYPSE ALICANTE, (asociación de técnicos de gestión del desarrollo local de la provincia de alicante). Nuestra Asociación, a nivel provincial, se ha creado en enero de 2013, (antes éramos una delegación sin personalidad jurídica independiente). A su vez, está integrada en la asociación de técnicos de gestión del desarrollo local de la Comunidad Valenciana. En la actualidad contamos con 54 socios, que además trabajamos en 20 municipios alicantinos y estamos en fase.

¿Quiénes somos? Somos profesionales, técnicos al servicio de la administración local, altamente cualificados y con un perfil multidisciplinar. Somos polivalentes y versátiles y en continua formación

Un error frecuente es asemejar al ADL con el agente de empleo, pero un Agente de desarrollo local se dedica a empleo y a cualquier área de la promoción económica en un ámbito territorial municipal o en mancomunidades.

Otro error frecuente es pensar que todos los ADLS están subvencionados. Es cierto que la primera vez que nos contratan suele ser a través de una subvención, pero posteriormente, son muchos los que hemos consolidado nuestro puesto al margen de la subvención. De hecho, de los cerca de 800 técnicos repartidos por toda la Comunidad Valenciana, sólo 270 están actualmente con contratos subvencionados.

Defendemos la prestación de servicios públicos de calidad tanto para nuestra propia entidad, como para el ciudadano. Por lo tanto tenemos dos clientes uno interno, el Ayuntamiento, al que asesoramos en todos los temas de promoción económica y empleo, le informamos legalmente, tramitamos subvenciones y proponemos las acciones más eficaces y eficientes, y otro externo, los desempleados, emprendedores, empresas, incluso las asociaciones empresariales, a los que informamos, asesoramos, formamos y motivamos para aumentar su cualificación y su competitividad económica. Hacemos de Ventanilla única, acercando los servicios de otras administraciones, dándoles un servicio global, evitándoles desplazamientos a la capital. En suma, servimos de puente entre las instituciones y el ciudadano desarrollando soluciones a medida del tejido económico y social de cada localidad.

Los rasgos que nos caracterizan y nos hacen competitivos frente a otros servicios son:

Conocemos muy bien el mapa social y económico del territorio donde trabajamos. Lo que tenemos muy en cuenta a la hora de planificar cualquier actividad o servicio y sacar el máximo potencial a cada actividad ya que se hace a medida.

Somos innovadores y versátiles. Adaptamos nuestro trabajo a los tiempos o necesidades de cada período económico, aplicando la imaginación y las buenas 
prácticas de otras experiencias exitosas. En épocas de bonanza podemos dedicarnos a promocionar el comercio o el turismo y en épocas de crisis, como la actual, nos volcamos más en programas de empleo y formación.

Somos "Buscadores de oro (recursos)" porque una parte importante de nuestro trabajo consiste en conseguir subvenciones y financiación, tanto para nuestro ayuntamiento, como para los particulares o asociaciones con las que trabajamos potenciando las sinergias para dar el máximo de calidad al mínimo coste.

En este sentido en mi propia Agencia Local de Petrer solemos duplicar el presupuesto municipal para actividades que se nos asigna, y eso sin contar con los programas de empleo, subvencionados al $100 \%$ y cuya cuantía, hasta el pasado año era muy elevada.

Somos profesionales muy rentables para la Administración: tenemos una parte de nuestra vida laboral subvencionada; no tenemos sueldos muy elevados (en comparación con otros técnicos de administración general) y como ya se ha detallado conseguimos dinero para financiar las actividades.

\section{ACTIVIDADES QUE VENIMOS REALIZANDO}

En agencias grandes, suelen disponer de técnicos especialistas en cada área. En ayuntamientos pequeños, el ADL se transforma en "supermán" para diseñar, poner en marcha y justificar los proyectos y servicios que se ponen en marcha en cualquier materia de promoción económica y empleo, con unos resultados más que aceptables. Además, tenemos la suerte de que el ciudadano es agradecido y así lo percibe, frente a quizás otros servicios de la administración que gozan de menos popularidad.

Algunas de las actividades que se llevan a cabo son:

Estudios de la estructura económica; ordenanzas municipales.

Informes técnicos.

Campañas de animación y promoción.

Atención al público.

Orientación laboral, talleres de motivación y búsqueda de empleo.

Cursos de formación, tanto para desempleados como para pymes.

Promoción y gestión de polígonos.

Asesoramiento a emprendedores.

Proyectos europeos.

Talleres de empleo, revitalización de barrios de acción preferente.

Actividades especificas con colectivos de difícil inserción laboral,

Actividades turísticas, desarrollo rural, etc.

Se trate de una Agencia grande o pequeña, con mayor o menor presupuesto, todos realizamos estas actividades en función de las necesidades coyunturales y de las características de nuestro municipio. 
También ejecutamos programas que vienen subvencionados desde la Conselleria, de cuantías importantes y que requieren una compleja gestión económica, de personas y de expedientes.

\section{VALORES QUE INSPIRAN NUESTRO TRABAJO}

Lo que sostiene este trabajo son unos valores profesionales que nos unen y nos motivan día a día y nos permiten seguir apostando por esta profesión aún en tiempo de crisis:

Vocación de Servicio. Nuestros servicios se prestan "con y para el público" y como administración pública, buscando mejorar la calidad de vida del ciudadano.

Legalidad. Informamos de la legalidad a nuestros clientes (externo e interno) y nuestras actividades y proyectos siempre se desarrollan bajo la premisa de la legalidad.

Eficacia y Eficiencia. Sabemos hacer "un duro de cuatro pesetas", buscamos financiación alternativa y aprovechamos todos los recursos técnicos, personales y materiales a nuestro alcance.

Cooperación, para maximizar recursos y llevar a buen puerto una actividad satisfaciendo el máximo de intereses. Siempre intentamos implicar en todos los proyectos a todos los agentes interesados en los mismos: otros departamentos municipales, asociaciones, otras administraciones o instituciones...todo aquel que pueda aportar algo. Solemos utilizar mucho la vía de los convenios.

Integración. Ligado al anterior siempre tratamos de integrar todo tipo de intereses y todo tipo de recursos y capacidades.

Inclusión. Estamos muy concienciados con el tema de los diferentes colectivos más desfavorecidos: mujeres con cargas familiares o maltratadas, discapacitados, jóvenes en riesgo de exclusión....y trabajamos en colaboración con los Servicios Sociales y las Asociaciones, realizando programas específicos para ellos.

Innovación. En dos vertientes: como pensamiento creativo, ya que siempre buscamos nuevas ideas, nuevos proyectos, buenas prácticas....y como implementadores de las nuevas tecnologías y de los cambios de nuevos conceptos, tanto en la propia administración en la que trabajamos, como a la hora de inculcarlo a nuestros clientes externos (pymes, emprendedores...).

Coordinación. Como solemos trabajar con grupos o con los demás agentes sociales, es frecuente que nos encarguemos de la coordinación de los proyectos en los que participamos, ya sea porque seamos los promotores o para garantizar la legalidad de la actuación.

Valor Social. No sólo buscamos la rentabilidad económica, también tratamos siempre de buscar la rentabilidad social de nuestros proyectos y que se beneficie el máximo de personas de cada actuación. 
Trabajar en red. RED AFIC; TOURIST-INFO; ADLYPSE...Hay muchas redes de profesionales del desarrollo local, porque sabemos que juntos, coordinados y con intercambio de experiencias trabajamos mejor.

Aprendizaje continuo y una mente abierta al cambio. Nunca sabemos bastante, y estamos en continua formación para poder ponerlo en práctica en nuestro trabajo.

Y LA PASIÓN. Nos encanta nuestro trabajo y se nota.

\section{Si hablamos De LOGROS Y RETOS}

A nivel particular, no se pueden resumir en unas líneas los beneficios alcanzados con los programas, proyectos europeos y actividades para fomentar el empleo que se han puesto en marcha en estos años, sin embargo, si que aquí entonamos un "mea culpa" por no haber sabido "vender" estos resultados que han repercutido positivamente en el desarrollo de nuestra provincia con el fin de haber reflejado el peso que nuestra profesión ha tenido y tiene en el progreso del territorio.

A nivel Colectivo es el hecho de haber sabido constituir asociaciones profesionales en el ámbito nacional, autonómico y provincial, por lo que se facilita el trabajo en red, la defensa de nuestros derechos profesionales, la visibilidad y la interlocución con otras administraciones y agentes sociales. Y en la misma línea haber iniciado el camino hacia nuestro colegio profesional.

Nuestro propósito, es seguir reivindicando y demostrando que las agencias de desarrollo local son necesarias y que este tipo de servicios deben ser una competencia municipal, porque es aquí donde mejor se puede actuar sobre el comercio, el turismo o la industria, y porque los vecinos-usuarios necesitan seguir atendidos.

\section{5. ¿CUÁl es La Situación ACtUAL?}

Estamos viviendo una situación de crisis económica y social sin precedentes, que requiere todavía más que se tome en serio el desarrollo local y que se proteja y atienda al ciudadano para generar riqueza y empleo.

Esta necesidad coincide con graves problemas de financiación en las administraciones locales y autonómicas. No han salido programas de empleo desde 2012 (a excepción de las prorrogas de AEDL y el programa de empleo autónomo y de la economía social) y por tanto, no hemos contado con los recursos y la relevancia que teníamos en materia de empleo en años anteriores.

Además, muchos compañeros orientadores, directores de casas de oficios, formadores, que eran fijos discontinuos en la administración también han perdido su medio de vida.

La nueva ley de bases, con sus ajustes financieros y competenciales pretende que sólo se mantenga en el ámbito local el turismo y los mercados y mer- 
cadillos, mientras que la materia de comercio, el empleo y el desarrollo económico empresarial será una competencia delegable y vinculada a la existencia de financiación, por lo que no está claro el mantenimiento de estos servicios, al menos, como en la actualidad.

Además la tendencia que se dibuja es suprimir las mancomunidades y empresas públicas que dupliquen servicios administrativos. Todos los ayuntamientos de menos de 5.000 y los de 20.000 habitantes, con endeudamiento, tampoco podrán tener competencias delegadas en estas materias y pasan a ser las diputaciones las que asumirán su papel.

En este contexto parece que al desarrollo local como se ha entendido hasta la fecha, como servicio público gestionado y ejecutado desde los municipios, le quedan los días contados. Como consecuencia nuestro colectivo afronta un periodo de renovación y se abre una puerta de reenfoque profesional transformándose bien en prestador de servicios externos para la administración competente y otros organismos, bien orientando sus talentos y vocación en servicios personales a ciudadanos como agentes que acompañan al cambio (Coach, Consultores, Formadores) o por último salir al exterior (como médicos o ingenieros...) para realizar proyectos de cooperación internacional.

Sin embargo, según el dictamen del comité de las regiones, sobre el desarrollo local participativo, publicado el 19 de enero de 2013 y que da una serie de recomendaciones políticas directas a los países y regiones miembros se muestra un hilo de esperanza. Estas son algunas de las ideas que propugna:

El desarrollo local participativo es un instrumento innovador y se plantea como una herramienta que va a permitir facilitar la realización a nivel local tanto de los objetivos fijados en el marco estratégico como en la agenda territorial de 2014 al 2020.

Destaca la importancia del desarrollo local para poder superar la actual crisis económica y de empleo, y, aunque parezca algo obvio, es necesario que se diga.

Propugna la importancia de la ventanilla única en la prestación de servicio y la simplificación de los trámites y además, destaca la importancia de que el ciudadano así lo perciba, para hacerle sentir más tranquilo en momentos de incertidumbre económica.

Establece que los proyectos deben ser integradores de los diferentes intereses e incluyentes respecto a los colectivos con mayores dificultades para la inserción.

Los proyectos que se implanten en territorios deben buscar eliminar las diferencias entre territorios urbanos y periferia y zonas rurales.

Dice que se debe introducir el desarrollo local participo como herramienta para poder obtener y gestionar líneas de financiación de distintos programas y fondos en un mismo proyecto, aumentando así, el porcentaje de financiación a los proyectos promovidos por asociaciones o grupos de acción local. 
Determina que es necesario que los proyectos, para ser más eficaces, deben basarse en la unión y la cooperación entre lo público, lo privado y los agentes sociales, incluso creando grupos de acción local que sean los promotores y gestores y que integren de este modo los distintos intereses en una unidad territorial.

Establece que los garantes de la legalidad y de la auditoría de cuentas en el proyecto, debe ser la parte pública, dando protagonismo como coordinadores del proyecto a los responsables técnicos desde la parte de la administración local.

Fija como optima, las unidades territoriales en territorios que vayan de 5000 a 150000 habitantes y excepcionalmente mayores y creando unidades inferiores para la ejecución.

Y propone un principio fundamental: que para que triunfen las políticas de desarrollo económico y social deben plantearse de abajo a arriba.

En definitiva:

Se están tratando de asentar las bases para obtener la financiación adecuada para los proyectos europeos que se planteen para los próximos 7 años y para alcanzar mejor los objetivos de cada programa operativo, primando a aquellos países o regiones que los planteen desde la óptica del desarrollo local participativo.

Esto quiere decir que si lo que más preocupa a la clase política en estos momentos es salir de la crisis y los temas de financiación, "deberían tener en cuenta" todas estas recomendaciones del Comité a la hora de la redacción definitiva de la nueva ley de bases de régimen local.

Por tanto y para concluir, creo que es importante que de este coloquio nacional de geógrafos salga un manifiesto conjunto en defensa del desarrollo local y que se eleve al legislador, para que tenga en cuenta todo lo expuesto y reconsidere el tema de las competencias permitiendo a los ayuntamientos seguir desarrollando competencias o actividades complementarias a las de otras administraciones en el ámbito del desarrollo económico, comercio, turismo y empleo. 